\title{
Caffeine Adsorption onto Bentonite Clay in Suspension and Immobilized
}

Giane Gonçalves Lenzi ${ }^{{ }^{*}}$

https://orcid.org/0000-0003-2065-9622

Maria Eduarda Kounaris Fuziki ${ }^{1}$

https://orcid.org/0000-0003-3871-6365

\section{Michel Zampieri Fidelis ${ }^{1}$}

https://orcid.org/0000-0003-0169-0843

Yuri Barros Fávaro ${ }^{1}$

https://orcid.org/0000-0001-6737-9332

\author{
Mauricio Aparecido Ribeiro ${ }^{1}$ \\ https://orcid.org/0000-0001-7314-0723
}

Eduardo Sidinei Chaves ${ }^{2}$

https://orcid.org/0000-0003-0982-3698

\author{
Ervin Kaminski Lenzi ${ }^{3}$ \\ https://orcid.org/0000-0003-3853-1790
}

\begin{abstract}
${ }^{1}$ Federal University of Technology, Department of Chemical Engineering, Ponta Grossa, Paraná, Brazil, ${ }^{2}$ Federal University of Santa Catarina, Department of Chemistry, Florianópolis, Santa Catarina, Brazil; ${ }^{3}$ State University of Ponta Grossa, Department of Physics, Ponta Grossa, Paraná, Brazil.
\end{abstract}

Received: 2018.11.10; Accepted: 2020.03.17.

*Correspondence: gianeg@utfpr.edu.br, Tel.: +55 (42) 3220-4800 (G.G.L.)

\section{HIGHLIGHTS}

- Adsorption process to remove contaminant of emerging concern - Caffeine.

- Bentonite clay has shown to be an efficient adsorbent in the caffeine removal.

- The adsorption process on immobilized bentonite is slower than in suspension.

\begin{abstract}
This study describes the use of bentonite in suspension for the caffeine adsorption (pollutant of emerging concern) by taking different conditions of the $\mathrm{pH}$, adsorbent mass, adsorbent calcination temperature and interferents into account. The results were compared with those obtained using bentonite immobilized in alginate beads. The acid medium has a greater efficiency for the caffeine adsorption and the adsorbent calcination temperature exerts, due to structural changes. Caffeine removal higher than $90 \%$ was obtained at optimized conditions. The Langmuir model indicated a better fit of the data and the adsorption capacity of caffeine onto bentonite. The bentonite immobilized led to a slower adsorption process in relation to the suspended.
\end{abstract}

Keywords: adsorption; caffeine removal; immobilized Bentonite; emerging pollutants.

\section{INTRODUCTION}

The growing industrialization and urbanization over all the planet have produced a large amount of chemical and biological substances discarded that end up reaching watercourses [1,2] with direct implications on the water quality, which is one of the most discussed and researched subjects. In this scenario, the socalled emerging contaminants or organic micropollutants such as pharmaceuticals, hygiene and beauty products, pesticides, hormones are known as endocrine disruptors (ED), and even at very low concentrations can case undesirable effects to the exposed organisms [3]. The presence of these compounds in analyses 
carried out in sewage treatment plants (STP) and water treatment plants (WTP) indicates that the current methods of treatment are not completely efficient in their removal. Bolong and coauthors showed that many EDs can produce harmful effects to aquatic biota, including changes in sex ratios of fish and changes in invertebrates habits $[4,5]$.

Caffeine is widely find in coffees, teas, nuts, cocoa, analgesics and stimulants; it acts in the organism as a stimulant of the central nervous system and in plants as a pesticide [6,7]. Consequently, due to the high consumption of caffeine and quantities dumped into water bodies, is indicated as a chemical marker to measure pollution in ground and surface water. It presents high solubility in water $\left(\mathrm{K}_{\mathrm{s}}>10,000 \mathrm{mg} \mathrm{L}^{-1}\right)$, low accumulation rate $\left(\log \mathrm{K}_{\mathrm{ow}}<0.5\right)$ and high removal rates in wastewater treatment plants (approximately $80 \%$ ). However, when metabolized by the human body, it becomes theophylline, theobromine, and paraxanthine, stable metabolites that are not efficiently removed in conventional plants of water treatment [8]. Thus, efficient alternatives of water treatment are necessary to improve the removal of these contaminants in the aquatic biota [9]. Several mechanisms were developed aiming at the caffeine removal in treatment plants, such as oxidative advanced processes [10], ozonation [11], membrane separation [12,13].

Among the treatment processes, the adsorption is one of the most efficient and economical methods for removal of contaminants with low concentrations. The most widely used adsorbent is activated carbon, due to its high surface area, surface reactivity and porosity. Nevertheless, it presents serious disadvantages such as relatively high price and adsorbent loss in the regeneration with chemicals $[14,15]$. Searching for highly efficient and economical adsorbents, Jiang and Ashekuzzaman [14] indicated that the treatment of micropollutants with clay minerals can be considered as a good alternative to activated carbon. These clays can be found on a large scale in most continents, they have low cost, high surface area and high porosity. Various types of clays have those characteristics, such as bentonite, kaolinite and vermiculite [16].

The bentonite clay is formed by raw clay minerals of the smectite group, and, in geological terms, is formed by montmorillonite, a material of volcanic origin, which after the devitrification process becomes fine particles, with high surface charge, cation exchange capacity, surface area and porosity [17]. The world bentonite production, in 2014, reached 12.2 million $\mathrm{t}$, with the United States (38.6\%) leading the production, followed by Turkey (9.1\%), Greece (8.3\%), Mexico (5.1\%) and Brazil (3.4\%) [18]. In this sense, this work proposes the use of bentonite in suspension and immobilized forms for the caffeine adsorption (pollutant of emerging concern) by taking different conditions of the $\mathrm{pH}$, adsorbent mass and adsorbent calcination temperature. Moreover, the influence of interferents $\left(\mathrm{Ba}^{2+}\right.$ and $\left.\mathrm{Pb}^{2+}\right)$ were evaluated.

\section{MATERIAL AND METHODS}

\section{Reagents and Instrumentation}

The reagents used in experiments were: caffeine $\left(\mathrm{C}_{8} \mathrm{H}_{10} \mathrm{~N}_{4} \mathrm{O}_{2}\right)$, supplied by Química Fina LTDA; Bentonite clay, supplied by Perquim; nitric acid $\left(\mathrm{HNO}_{3}\right)$, supplied by Merck; sodium alginate, supplied by Sigma-Aldrich; calcium chloride $\left(\mathrm{CaCl}_{2} .2 \mathrm{H}_{2} \mathrm{O}\right)$, supplied by BIOTEC; lead nitrate $\left(\mathrm{Pb}\left(\mathrm{NO}_{3}\right)_{2}\right)$, supplied by BIOTEC and (barium nitrate $\left(\mathrm{Ba}\left(\mathrm{NO}_{3}\right)_{2}\right)$, supplied by Perquim. The caffeine removal was monitored at 267.0 $\mathrm{nm}$ in a UV-Vis FEMTO Spectrophotometer

\section{Adsorbent}

The bentonite was the adsorbent used, with no heat treatment and calcined at 500,700 and $900^{\circ} \mathrm{C}$, for $5 \mathrm{~h}$ under static air atmosphere. Besides being used in suspension, tests were performed with bentonite immobilized on calcium alginate beads. Immobilization was performed as described previously for biosorbent [19] and photocatalyst [20]. For bentonite immobilization, $4.0 \mathrm{~g}$ of sodium alginate and $8.0 \mathrm{~g}$ of bentonite were added to $200 \mathrm{~mL}$ of ultrapure water. The mixture was agitated and trickled in $2 \%(\mathrm{~m} / \mathrm{v}) \mathrm{CaCl}_{2}$ solution. When in contact with the solution, calcium alginate immobilized bentonite beads were formed, by replacing $\mathrm{Na}^{+}$ions with $\mathrm{Ca}^{2+}$. The beads were immersed into the solution overnight and then well washed and stored in ultrapure water for later testing.

\section{Adsorbent Characterization}

Thermogravimetric analysis (TGA) of the non-calcined bentonite clay sample was performed using the SHIMADZU-Thermo-Model TGA-50 equipment. Approximately $10 \mathrm{mg}$ was subjected to a heating rate of

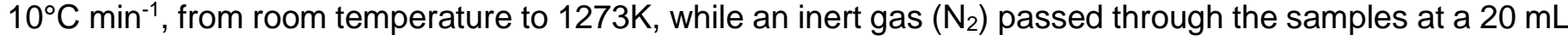


$\min ^{-1}$ flow rate. The analysis of infrared spectroscopy (FTIR) were performed in an infrared spectrometer equipment (Varian 7000) with Fourier transform.

\section{Estimation of the immobilized bentonite mass in the beads}

The estimate mass of the bentonite, immobilized on the alginate beads, was obtained by the mass difference, before and after the calcination. Calcination was conducted on muffle, under static air atmosphere and subjected to a heating pad, from room temperature up to $773 \mathrm{~K}$, for $2 \mathrm{~h}$. The analysis was performed at least in triplicate.

\section{Kinetic study}

To assess the caffeine adsorption kinetics on bentonite, experiments were carried out in different conditions of $\mathrm{pH}$, adsorbent calcination temperature and mass. In all experiments, $500 \mathrm{~mL}$ of caffeine solution, with a concentration of $20 \mathrm{mg} \mathrm{L}^{-1}$ were placed in contact with the adsorbent under agitation for $24 \mathrm{~h}$. The temperature was maintained at $298 \mathrm{~K}$ and the agitation was approximately $200 \mathrm{rpm}$. Variation of $\mathrm{pH}$ occurred between 2 and 6.5 and the adjustment was accomplished by the addition of diluted solution of nitric acid.

For the equilibrium study, the adsorbent mass used in the tests varied between $0.250 \mathrm{~g}$ and $0.600 \mathrm{~g}$ (temperature at 298K). During the experiments, aliquots of the samples were collected at regular time intervals. The aliquots were centrifuged and then filtered with an inert millipore filter of $22 \mu \mathrm{m}$ of pore. The concentration of samples was then determined by Spectrometry in the UV region, at wavelength 267. $\mathrm{nm}$. The optimum conditions found $(\mathrm{pH}$, calcination temperature and adsorbent mass) have been selected for experiments with the immobilized bentonite.

\section{Influence of Interferents}

Experiments were carried out to assess the effects the competition between ions $\left(\mathrm{Pb}^{2+}\right.$ and $\left.\mathrm{Ba}^{2+}\right)$ have on the kinetics of caffeine adsorption. These tests followed a methodology similar to that described previously, with optimized conditions of $\mathrm{pH}$, calcination temperature and adsorbent mass. For the tests involving heavy metals, three solutions were prepared: Solution 1: caffeine with $\mathrm{Pb}^{2+}\left(25 \mathrm{mg} \mathrm{L}^{-1}\right)$; Solution 2: caffeine with $\mathrm{Ba}^{2+}\left(25 \mathrm{mg} \mathrm{L}^{-1}\right)$ and Solution 3: caffeine and the two metals $\left(\mathrm{Pb}^{2+}\right.$ and $\left.\mathrm{Ba}^{2+}\right)$, both at concentration of $25 \mathrm{mg} \mathrm{L}^{-1}$. The solutions were prepared from the salts $\mathrm{Pb}\left(\mathrm{NO}_{3}\right)_{2}$ and $\mathrm{Ba}\left(\mathrm{NO}_{3}\right)_{2}$. In the three solutions, the concentration of caffeine was the same $\left(20 \mathrm{mg} \mathrm{L}^{-1}\right)$.

\section{RESULTS}

\section{Characterization}

The TGA/DTGA result of bentonite clay is shown in Figure 1. The FTIR spectra of bentonite clay, before and after, the process of caffeine adsorption are showed in Figure 2.

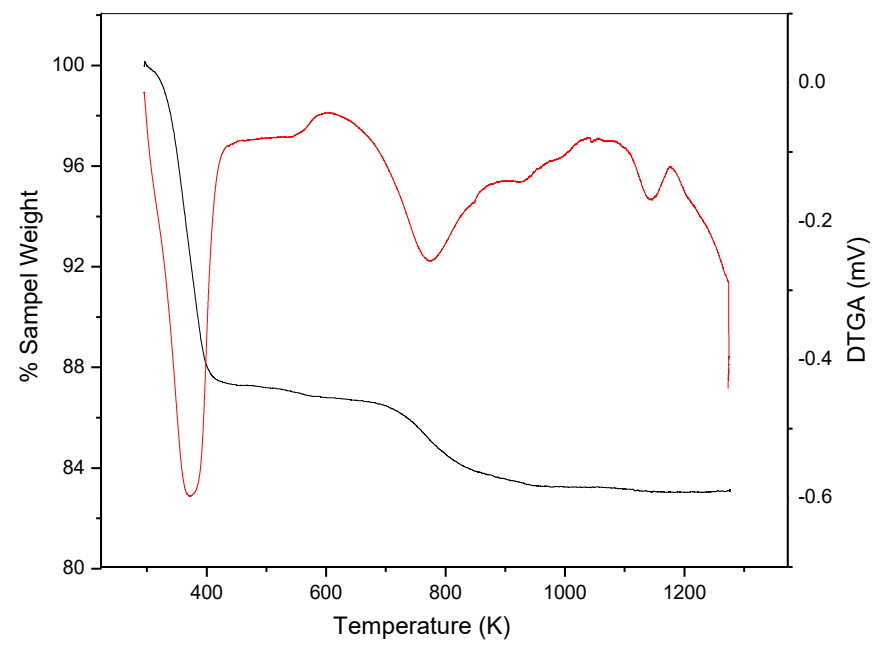

Figure 1. TGA/DTGA data for Bentonite sample (non-calcined). 


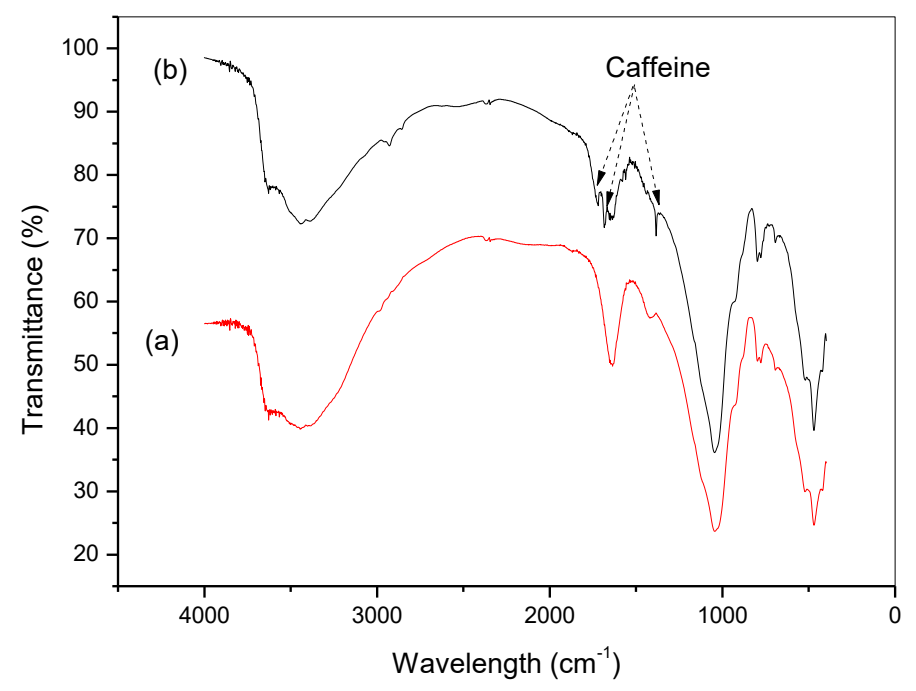

Figure 2. FTIR spectrum (a) before and (b) after caffeine adsorption (Bentonite powder).

The results $\mathrm{pH}$ and thermal treatment effect are presented in the Figure 3 and 4, respectively.

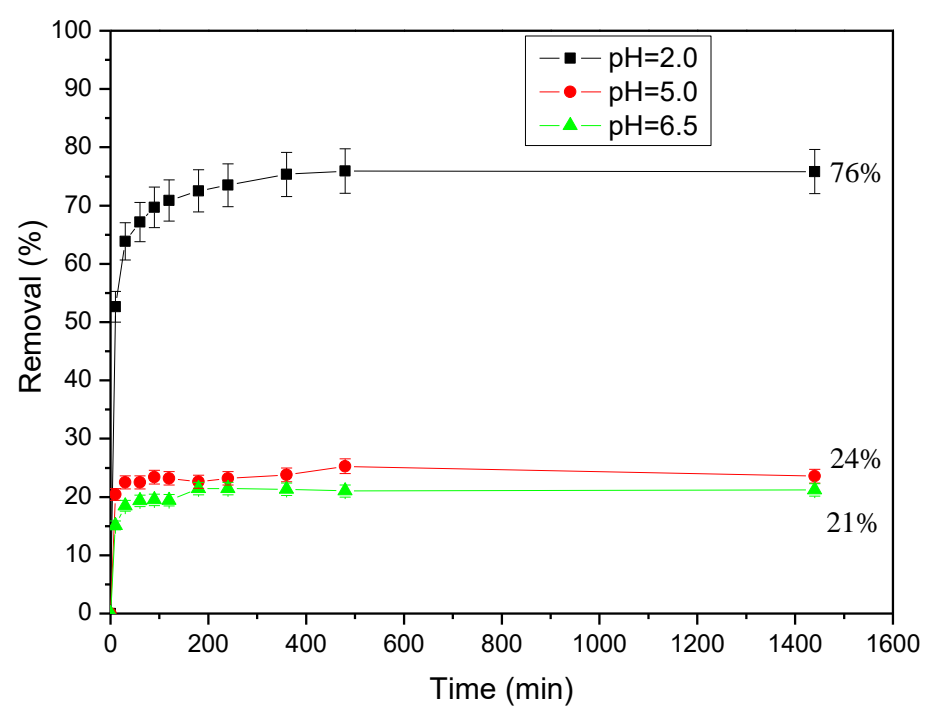

Figure 3. Effect of $\mathrm{pH}$ on kinetics of caffeine removal. Caffeine concentration $20 \mathrm{mg} \mathrm{L}^{-1}$ and $0.5 \mathrm{~g} \mathrm{~L}^{-1}$ of bentonite calcined at $773 \mathrm{~K}$. The error bars represent the standard deviation of 3 measurements.

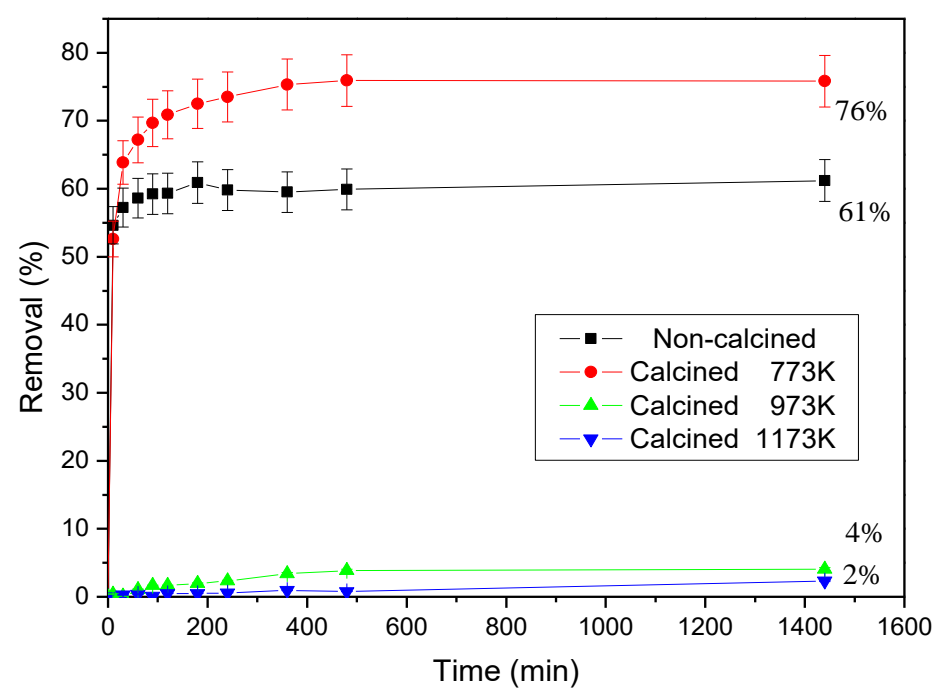

Figure 4. Effect of bentonite calcination temperature. Caffeine concentration $20 \mathrm{mg} \mathrm{L}^{-1}, \mathrm{pH}=2,0$ and $0.5 \mathrm{~g} \mathrm{~L}^{-1}$ of bentonite. 
The results of adsorbent mass influence on the caffeine adsorption kinetics (Figure 5).



Figure 5. Effect of adsorbent mass variation on caffeine removal (Caffeine concentration $20 \mathrm{mg} \mathrm{L}^{-1}$, $\mathrm{T}$ calcination $=$ $\left.500^{\circ} \mathrm{C}, \mathrm{pH}=2,0\right)$. The error bars represents the standard deviation of 3 measurements.

The Table 1 present the parameters of the Langmuir and Freundlich isotherm.

Table 1. Parameters of the isotherm models for caffeine adsorption by bentonite powder.

\begin{tabular}{|c|c|c|c|c|c|c|}
\hline \multicolumn{4}{|c|}{ Langmuir Model } & \multicolumn{3}{|c|}{ Freundlich Model } \\
\hline$K_{L}\left(\mathrm{~L} \mathrm{mg}^{-1}\right)$ & $q_{\max }\left(\mathrm{mg} \mathrm{g}^{-1}\right)$ & $\mathbf{\mathbf { R } _ { \mathrm { L } }}$ & $\mathbf{R}^{2}$ & $K_{f}\left(\mathrm{mg} \mathrm{g}^{-1}\right)$ & $n$ & $\mathbf{R}^{2}$ \\
\hline 0.7186 & 41.667 & 0.0651 & 0.9671 & 18.5097 & 2.8050 & 0.7928 \\
\hline
\end{tabular}

Tests performed with $\mathrm{Ba}^{2+}$ and $\mathrm{Pb}^{2+}$ interferent are shown in Figure $6 \mathrm{~A}(\mathrm{~Pb}$ and $\mathrm{Ba})$ and Figure $6 \mathrm{~B}$ (Caffeine).

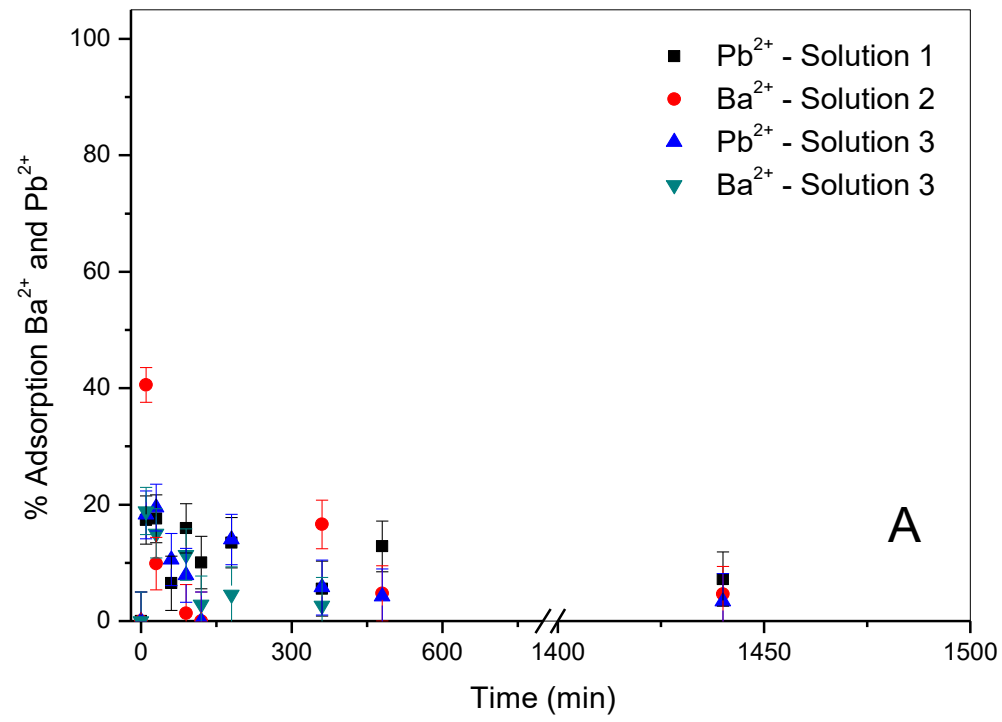






Figure 6. Effect of Interferents on Caffeine adsorption ( $\mathrm{T}$ calcination $=773 \mathrm{~K} ; \mathrm{pH}=2.00 .8 \mathrm{~g} \mathrm{~L}^{-1}, \mathrm{Ba}^{2+}$ and $\mathrm{Pb}^{2+} 25 \mathrm{mg}$ $\left.\mathrm{L}^{-1}\right)$ A) Interferents Results and B) Caffeine results. (Solution 1: Solution $\mathrm{Pb}^{2+}\left(25 \mathrm{mg} \mathrm{L}^{-1}\right)+$ Caffeine; Solution 2: $\mathrm{Ba}^{2+}$ $\left(25 \mathrm{mg} \mathrm{L}^{-1}\right)+$ Caffeine; Solution3: $\mathrm{Ba}^{2+}\left(25 \mathrm{mg} \mathrm{L}^{-1}\right)+\mathrm{Pb}^{2+}\left(25 \mathrm{mg} \mathrm{L}^{-1}\right)+$ Caffeine $)$.

The results on immobilization Influence are shows in the Figure 7.


Figure 7. Caffeine adsorption by Bentonite clay in suspension and immobilized. $\mathrm{pH}=2.0$; Adsorbent: Bentonite calcined at $773 \mathrm{~K}$ in suspension and immobilized.

\section{DISCUSSION}

The TGA/DTGA result of bentonite clay, without prior thermal treatment, presented a profile basically divided into two regions of mass loss, as shown in Figure 1.

These regions are in the following temperature ranges: $298 \mathrm{~K}$ to $416 \mathrm{~K}$ and 416 to $973 \mathrm{~K}$, with maximum temperatures at 347 and $723 \mathrm{~K}$, respectively. The mass loss observed in the low temperature region (room temperature up to $416 \mathrm{~K}$ ) are assigned to adsorbed water on the surface of the clay [21].

The FTIR spectra of bentonite clay before and after the process of caffeine adsorption are showed in Figure 2. The spectra indicate the presence of different functional groups, highlighting the complex nature of the adsorbent. The FTIR spectrum before adsorption has a wide band at 3623 and $3463 \mathrm{~cm}^{-1}$, indicating the presence of the isomorphic substitution of octahedral cations $\mathrm{Al}^{3+}$ by $\mathrm{Fe}^{2+}$ or $\mathrm{Mg}$, and of lengthening of $\mathrm{OH}$ group, respectively. The band at $470 \mathrm{~cm}^{-1}$, is attributed to band enlargement of Si-O-Si [22]. The FTIR 
spectrum for bentonite after the adsorption process showed a significant difference in the bands, indicating the presence of adsorbed caffeine, more intensely in the region 1700 to $1300 \mathrm{~cm}^{-1}$ [23].

\section{pH influence}

The results, presented in Figure 3, show the $\mathrm{pH}$ influence in the caffeine adsorption on bentonite. This result indicated that adsorption is favored at low $\mathrm{pH}$ values. For solution $\mathrm{pH}$ equal to 2.0, the removal after 24 hours was much higher than the removal for $\mathrm{pH} 5.0$ and 6.5. Couto $\mathrm{Jr}$ and coauthors [24] studied caffeine adsorption on activated carbon; the highest caffeine removal at acidic $\mathrm{pH}$ (3.0 and 4.9) and lower removal at basic $\mathrm{pH}(10.0)$ were observed. According to the author, the adsorption process studied is strongly influenced by the $\mathrm{pH}$, since this parameter is directly related to the $\mathrm{pH}_{\mathrm{Pzc}}$ of the surface and to the $\mathrm{pKa}$ of caffeine. Then, the following experiments were performed at $\mathrm{pH}=2.0$

\section{Thermal treatment Influence}

The Thermal treatment (calcination) conducted in bentonite had a strong impact on the adsorption capacity, as shown in Figure 4. The bentonite calcined at $773 \mathrm{~K}$ presented the best result, in comparison with the other adsorbents used in the tests. However, the adsorbents that were submitted to thermal treatment at temperatures higher than $973 \mathrm{~K}$ showed a reduced adsorption capacity, possibly due to the modification of the adsorbent structure.

This is described by Yamamoto and coauthors [25] at calcination temperatures greater than 573K. The calcination of montmorillonite, a major component of bentonite, at temperatures above $573 \mathrm{~K}$ definitively changes the structure of the material, making the dehydration process irreversible and decreasing the distance between the layers of the montmorillonite structure.

\section{Mass adsorbent influence}

The adsorbent mass used in the process affects the kinetics of caffeine adsorption (Fig. 5). The results obtained in the equilibrium study indicated that for a bentonite mass (powder) of $0.250 \mathrm{~g}$ the adsorption in 24 hours was approximately $76 \%$. However, from a mass of $0.400 \mathrm{~g}$ the influence was not so significant $(0.400-0.600 \mathrm{~g})$, being the adsorption in $24 \mathrm{~h}$ around 91 to $94 \%$. However, was observed that in the initial minutes adsorption kinetics was rapid for all bentonite masses studied. In approximately 90 minutes, the adsorption obtained was final practically (24 hours).

\section{Langmuir and Freundlich Models}

The Langmuir and Freundlich isotherm models were applied to describe the caffeine adsorption by bentonite (Table 1). The Langmuir isotherm model was applied to analyze the data obtained in the equilibrium study, according to the equation (1),

$$
\frac{C_{e}}{q_{e}}=\frac{1}{q_{\max }} C_{e}+\frac{1}{K_{L} q_{\max }},
$$

Where, $q_{\max }$ is the maximum capacity of adsorption $\left(\mathrm{mg} \mathrm{g}^{-1}\right)$ and $\mathrm{K}_{\mathrm{L}}$ is the Langmuir constant $\left(\mathrm{L} \mathrm{mg}^{-1}\right)$ related to adsorption energy. The linear plot of $\mathrm{C}_{\mathrm{e}} / \mathrm{q}_{\mathrm{e}}$ versus $\mathrm{C}_{\mathrm{e}}$ is used for $\mathrm{q}_{\max }$ and $\mathrm{K}_{\mathrm{L}}$ calculation.

The obtained maximum adsorption capacity $\left(q_{\max }\right)$ in this study was $41.667 \mathrm{mg} \cdot \mathrm{g}^{-1}$ and this value is comparable to adsorption capacity obtained at the literature. For example, the adsorption capacity of caffeine on Grape Stalk was $68.633 \mathrm{mg} \cdot \mathrm{g}^{-1}[26]$.

The essential characteristics of the Langmuir isotherm can be expressed by means of a dimensionless constant separation factor $\left(R_{\mathrm{L}}\right)$, defined as equation 2 :

$$
R_{L}=\frac{1}{1+K_{L} C_{0}}
$$

The $R_{L}$ value indicates whether the isotherm adsorption is favorable $\left(0<R_{L}<1\right)$, unfavorable $\left(R_{L}>1\right)$, linear $\left(R_{L}=1\right)$ or irreversible $\left(R_{L}=0\right)$ [27]. The $R_{L}$ value obtained for the caffeine adsorption by bentonite in suspension was 0.0651 , indicating that the adsorption process is favorable.

The Freundlich isotherm model was also applied to the data obtained, according to the equation 3:

$$
\log q_{e}=\log \left(K_{F}\right)+\frac{1}{n} \log C_{e},
$$


where $\mathrm{K}_{\mathrm{F}}$ and $\mathrm{n}$ are Freundlich constants that are respectively defined as the adsorption capacity and intensity. The parameters and their respective correlation coefficients $\left(R_{2}\right)$ obtained for the isotherms models applied are shown in Table 1.

\section{Influence of Interferents}

In tests conducted with interferent, $\mathrm{Ba}^{2+}$ and $\mathrm{Pb}^{2+}$, (Figure 6 ) indicated a low adsorption of metals (Figure 6-A). The $\mathrm{pH}$ condition used in the test may be responsible for the low adsorption of metals, since, according to ljagbemi and coauthors [28] on adsorption of $\mathrm{Cu}^{2+}$ and $\mathrm{Ni}^{2+}$ in montmorillonite, low $\mathrm{pH}$ values lead to higher concentration of $\mathrm{H}^{+}$ions on the adsorbent surface, which compete with the metals ions. Other processes such as photocatalysis, which has adsorption on the solid surface as one of the steps, also indicate that an acidic $\mathrm{pH}$ is not favorable for Barium removal [29].

On the other hand, the metals presence did not affect the caffeine removal (Figure 6-B), demonstrating that there was no competition between caffeine and the metals for the bentonite adsorption. Even the presence of the two metals in solution, simultaneously, did not reduce the capacity of caffeine removal by adsorption. We need to consider that the $\mathrm{NO}_{3}{ }^{-}$ions present in the medium did not interfere in the adsorption process.

In a study on caffeine adsorption in activated carbons, Couto Jr and coauthors [24] evaluated the effect of water hardness on caffeine removal. The results indicated that the presence of $\mathrm{Ca}^{2+}$ and $\mathrm{Mg}^{2+}$ ions reduce caffeine removal by adsorption, probably by increasing its solubility caused by the presence of ions in solution.

\section{Immobilization- Influence}

Based on the results of bentonite concentration in the bead $(0.072 \mathrm{~g}$ bentonite $/ \mathrm{g}$ bead), for comparison, approximately the same mass used in suspension was estimated for the tests. The results of adsorption kinetics of bentonite, calcined at $500{ }^{\circ} \mathrm{C}$, in suspension and immobilized in calcium alginate are shown in Figure 7. We can observe that the immobilization of the adsorbent significantly affected the adsorption process, making the caffeine removal rate slower.

Zarzar and coauthors [30] investigated the caffeine adsorption on alginate and chitosan beads in different conditions. In the case of alginate beads, the maximum removal obtained in the tests was less than $6 \%$. The study about the effect of $\mathrm{pH}$ showed that the alginate beads had better removal at $\mathrm{pH} 6$, and the adsorption capacity decreased considerably in lower $\mathrm{pH}$ values [28].

Nevertheless, the results indicate that the removal observed in the tests with immobilized bentonite is mostly due to the caffeine adsorption in the clay, and not in the alginate. The decrease in the removal speed occurs because the caffeine is not directly in touch with bentonite since the beginning of the process. The diffusion of caffeine inside the bead is possibly a limiting step for the adsorption process, making the removal slower. In addition, alginate beads can release calcium, which affects the adsorption of caffeine.

\section{CONCLUSION}

Bentonite clay has shown to be an efficient adsorbent in the caffeine removal, due to its low cost and the possibility of immobilization. Optimization of the parameters indicated that the $\mathrm{pH} 2.0$ is best suited for the process of caffeine adsorption and the adsorbent mass influences significantly on this process. With the thermal treatment (calcination) a change occurred in the structure of adsorbent, affecting the process. The immobilization of bentonite in calcium alginate slowed down the process, and in 1440 min the caffeine adsorption on immobilized bentonite decreased $19 \%$ compared to bentonite in suspension. The Langmuir model presented a better fit for the data obtained and the adsorption capacity of caffeine onto bentonite was $41.667 \mathrm{mg} \mathrm{g}^{-1}$.

Acknowledgments: The authors would like to thank Brazilian Agencies CAPES and CNPq for financial support of this study and Centro de Caracterização Multiusuário em Pesquisa e Desenvolvimento de Materiais $\left(\mathrm{C}^{2} \mathrm{MMa}\right)$.

\section{REFERENCES}

1. Cui L, Shi J. Urbanization and its environmental effects in Shanghai, China. Urban Clim. 2012 Dec; 2: 1-15.

2. Teh T, Nik Norulaini NAR, Shahadat M, Wong Y, Mohd Omar AK. Risk assessment of metal contamination in soil and groundwater in Asia: a review of recent trends as well as existing environmental laws and regulations. Pedosphere. 2016 Aug;26(4):431-50. 
3. Bila DM, Montalvão AF, Dezotti M. 17th World Ozone Congress, Strasbourg, France, 2005 Aug.

4. Bolong N, Ismail AF, Salim MR, Matsuura T. A review of the effects of emerging contaminants in wastewater and options for their removal. Desalination. 2009 Apr;239(1-3):229-46.

5. Huber MM, Canonica S, Park GY, Guten U. Oxidation of Pharmaceuticals during Ozonation and Advanced Oxidation Processes. Environ Sci Technol. 2003 Mar; 37 (5): 1016-1024. doi:10.1021/es025896h.

6. Pavel I, Szeghalmi A, Moigno D, Cîntă S, Kiefer W. Theoretical and pH dependent surface enhanced Raman spectroscopy study on caffeine. Biopolymers. 2003; 72(1): 25-37. doi:10.1002/bip.10248.

7. Pollack K, Balazs K, Ogunseitan O. Proteomic assessment of caffeine effects on coral symbionts. Environ Sci Technol. 2009 Mar; 43 (6): 2085-2091. doi:10.1021/es802617f.

8. Dong ZB, Liang, YR, Fan, FY, Ye JH, Zheng XQ, Lu JL. Adsorption behavior of the catechins and caffeine onto polyvinylpyrrolidone. J Agric Food Chem. 2011 Apr; 59(8):4238-47. doi:10.1021/jf200089m.

9. Ma H, Burger C, Hsiao BS, Chu B. Highly permeable polymer membranes containing directed channels for water purification. ACS Macro Lett. 2012 May; 1(6):723-26.

10. Afonso-Olivares C, Fernandes-Rodriguez C, Ojeda-González RJ, Sosa-Ferreira Z, Santana-Rodriguez JJ, Rodriguez JMD. Estimation of kinetic parameters and UV doses necessary to remove twenty-three pharmaceuticals from pre-treated urban wastewater by UV/H2O2. J Photochem Photobiol A Chem. 2016 Jun; 329: 130-8. doi:10.1016/j.jphotochem.2016.06.018

11. Ternes TA, Stüber J, Herrmann N, Mcdowell D, Ried A, Kampmann M, Teiser B. Ozonation: a tool for removal of pharmaceuticals, contrast media and musk fragrances from wastewater? Water Res. 2003 Apr;37(8):1976-82. doi:10.1016/S0043-1354(02)00570-5.

12. Mahlangu TO, Msagati TAM, Hoek EMV, Verliefde ARD, Mamba BB. Rejection of pharmaceuticals by nanofiltration (NF) membranes: effect of fouling on rejection behaviour. Phys Chem Earth, Parts A/B/C. 2014 Nov; 76-78: 28-34.

13. Mestre AS, Pires RA, Aroso I, Fernandes EM, Pinto ML, Reis RL, Andrade MA, Pires J, Silva SP Carvalho AP. Activated carbons prepared from industrial pre-treated cork: sustainable adsorbents for pharmaceutical compounds removal. Chem Eng J. 2014 Oct;253:408-17.

14. Jiang, JQ, Ashekuzzaman SM. Development of novel inorganic adsorbent for water treatment. Curr Opin Chem Eng. 2012 May;1(2):191-9.

15. Özdemir Y, Dogan M, Alkan, M. Adsorption of cationic dyes from aqueous solutions by sepiolite. Microporous Mesoporous Mater. 2006 Nov;96(1-3):419-27.

16. Bautista FM, Campelo JM, Luna D, Luque J, Marinas JM. Vanadium oxides supported on $\mathrm{TiO}_{2}$-sepiolite and sepiolite: Preparation, structural and acid characterization and catalytic behavior in selective oxidation of toluene. Appl Catal A Gen. 2007Jun;325(2):336-44.

17. Barbosa CS, Santana SAA, Bezerra CWB, Silva, HAS. Removal of phenolic compounds from aqueous solutions using activated carbon prepared from water hyacinth (Eichhornia crassipes): kinetic and thermodynamic equilibrium studies. Quím Nova. 2014 May-Jun;37(3):447-53.

18. Departamento Nacional De Produção Mineral (DNPM). Sumário Mineral. Brasília, 2015.

19. Arica MY, Bayramoğlu G, Yilmaz M, Bektaş S, Genç Ö. Biosorption of $\mathrm{Hg}^{2+}, \mathrm{Cd}^{2+}$, And $\mathrm{Zn}^{2+}$ by Ca-alginate and immobilized wood-rooting fungus Funalia Trogi. J Hazard Mater. 2004 Jun;109(1-3):191-9. doi: 10.1016/j.jhazmat.2004.03.017.

20. Liu YG, Hu XJ, Wang H, Chen AW, Liu SM, Guo YM, He Y, Hu X, Li J, Liu SH, Wang YQ, Zhou L. Photoreduction of $\mathrm{Cr}(\mathrm{VI})$ from acidic aqueous solution using $\mathrm{TiO}_{2}$-impregnated glutaraldehyde-crosslinked alginate beads and the effects of $\mathrm{Fe}$ (III) ions. Chem Eng J. 2013 Jun;226:131-8.

21. Gonçalves G, Lenzi MK, Santos OAA, Jorge LMM. Preparation and characterization of nickel based catalysts on silica, alumina and titania obtained by sol-gel method. J Non-Cryst Solids. 2006 Sep; 352(32):3697-3704.

22. Hayati-Ashtiani M. Characterization of nano-porous bentonite (montmorillonite) particles using FTIR and BET-BJH analyses. Part Part Syst Charact. 2012 Aug; 28(3-4): 71-76. doi:10.1002/ppsc.201100030.

23. Ohnsmann J, Quintás G, Garrigues S, De La Guardia M. Determination of caffeine in tea samples by Fourier transform infrared spectrometry. Anal Bioanal Chem. 2002 Oct; 374(3):561-565. doi: 10.1007/s00216-002-15038.

24. Couto OM, Matos I, da Fonseca IM, Arroyo PA, da Silva EA, Dornellas de Barros MAS. Effect of solution pH and influence of water hardness on caffeine adsorption onto activated carbons. Can J Chem Eng. 2015 Jan;93(1):6877.

25. Yamamoto K, Shiono T, Matsui $\mathrm{Y}$, Yoneda M. Changes the structure and caffeine adsorption property of calcined montmorillonite. Int J GEOMATE. 2016 Aug; 11(24):2301-6.

26. Portinho R, Zanella O, Féris LA. Grape stalk application for caffeine removal through adsorption. J Environ Manage. 2017 Nov; 20(1):178- 87. 
27. Fontana KB, Chaves ES, Kosera VS, Lenzi GG. Barium removal by photocatalytic process: An alternative for water treatment. J Water Process Eng. 2018 Apr; 22:163-71.

28. ljagbemi CO, Baek MH, Kim DS. Montmorillonite surface properties and sorption characteristics for heavy metals removal from aqueous solutions. J Hazard Mater. 2009 Jul; 166(1): 538-546. doi: 10.1016/j.jhazmat.2008.11.085.

29. Yao ZY, Qi JH, Wang LH. Equilibrium, kinetic and thermodynamic studies on the biosorption of $\mathrm{Cu}$ (II) onto chestnut shell. J Hazard Mater. 2010 Feb; 174(1-3):137-43.

30.Zarzar A, Hong M, Llanos BP, Navarro AB. Insights into the eco-friendly adsorption of caffeine from contaminated solutions by using hydrogel beads. J Environ Anal Chem. 2015 Jan;2(4):1-5.

(C) (1) 8) 2020 by the authors. Submitted for possible open access publication under the terms and 